\title{
EFEITO DO TRATAMENTO DE SEMENTES COM INSETICIDAS NO CONTROLE DE PRAGAS INICIAIS E NA QUALIDADE FISIOLÓGICA DAS SEMENTES EM GIRASSOL
}

\author{
A.F. Bueno ${ }^{1}$,J.F. Sales ${ }^{2}$, R.C.O.F. Bueno ${ }^{3 *}$, R.G. da Costa ${ }^{2}$, S.S. Vieira ${ }^{4}$ \\ ${ }^{1}$ Embrapa Soja, Rod. Carlos João Strass, s/no, Distrito de Warta, CEP 86001-970, Londrina, PR, Brasil, E-mail: \\ adeney@cnpso.embrapa.br
}

\section{RESUMO}

Avaliou-se o uso de inseticidas em tratamento de sementes de girassol no controle das pragas Cerotoma arcuatus (Olivier) (Coleoptera: Chrysomelidae), Bemisia tabaci (Gennadius) (Hemiptera: Aleyrodidae), Anticarsia gemmatalis Hübner (Lepidoptera: Noctuidae) e Spodoptera frugiperda (J.E. Smith) (Lepidoptera: Noctuidae) e a influência desses inseticidas na qualidade fisiológica das sementes, durante o armazenamento. Os resultados obtidos mostraram que tiodicarbe $600 \mathrm{~g}$ i.a./ $100 \mathrm{~kg}$ de sementes proporcionou aproximadamente 80, 100 e 85\% de controle de A. gemmatalis de $1^{\circ}$ ínstar, S. frugiperda de $2^{\circ}$ ínstar e adultos de C. arcuatus, respectivamente. Entretanto, esse mesmo tratamento foi ineficiente no controle de lagartas de $S$. frugiperda de $3^{\circ}$ ínstar e de $B$. tabaci. No controle de adultos de C. arcuatus, além de tiodicarbe $600 \mathrm{~g}$ i.a. $/ 100 \mathrm{~kg}$ sementes que apresentou bons resultados, tiodicarbe + imidacloprido 157,5 + 52,5 g i.a., tiametoxam 210 e 280 g i.a., imidacloprido 245 e fipronil 50 g i.a./100 kg de sementes apresentaram eficiência acima de $80 \%$ no controle dessa praga. No controle da A. gemmatalis apenas fipronil 50 g i.a./100 kg sementes e azadiractina 10 e 20 g. i.a./100 kg de sementes proporcionaram valores menores que $80 \%$ de controle, nas doses testadas, enquanto que, para o manejo da mosca-branca, nenhum dos tratamentos estudados proporcionou controle superior a $80 \%$. Nenhum dos inseticidas avaliados nos diferentes tempos de armazenamento (até quatro meses após o tratamento) prejudicou a germinação e a emergência das sementes.

PALAVRAS-CHAVE: Cerotoma arcuatus, Bemisia tabaci, Anticarsia gemmatalis, Spodoptera frugiperda, Heliantus annuus.

\begin{abstract}
THE EFFECT OF VARIOUS INSECTICIDES ON THE CONTROL OF INITIAL PESTS AND ON THE PHYSIOLOGICAL QUALITY OF SUNFLOWER SEEDS. The aim of this study was to test various insecticides in the treatment of sunflower seeds for the control of Cerotoma arcuatus (Olivier) (Coleoptera: Chrysomelidae), Bemisia tabaci (Gennadius) (Hemiptera: Aleyrodidae), Anticarsia gemmatalis Hübner (Lepidoptera: Noctuidae) and Spodoptera frugiperda (J.E. Smith) (Lepidoptera: Noctuidae), and assessing their influence on the physiological quality of seeds during storage. The results showed that tiodicarb 600 g.a.i. $/ 100 \mathrm{~kg}$ of seeds achieved close to 80 , 100 and $85 \%$ of control against first-instar A. gemmatalis, second instar S. frugiperda and adult C. arcuatus, respectively. However, this treatment was inefficient against third instar S. frugiperda and B. tabaci. Tiodicarb + imidacloprid $157.5+52.5$; thiamethoxan 210; thiamethoxan 280; imidacloprid 245 and fipronil 50 g.a.i. $/ 100 \mathrm{~kg}$ of seeds also achieved $80 \%$ control against C. arcuatus adults. Against A. gemmatalis, only fipronil 50 g.a.i. and azarachtin 10 and 20 g.a.i. $/ 100 \mathrm{~kg}$ of seeds did not achieve more than $80 \%$ control. Against $B$. tabaci no tested treatment reached $80 \%$ of efficacy. None of the tested insecticides harmed seed germination or emergence during the different storage periods (up to 4 months after seed treatment).
\end{abstract}

KEYWORDS: Cerotoma arcuatus, Bemisia tabaci, Anticarsia gemmatalis, Spodoptera frugiperda, Heliantus annuus.

\footnotetext{
${ }^{2}$ CEFET Rio Verde, GO, Brasil.

${ }^{3}$ Universidade de Rio Verde, Rio Verde, GO, Brasil.

${ }^{4}$ Universidade do Estado de Santa Catarina, Centro de Ciências Agroveterinárias, Florianópolis, SC, Brasil. *Bolsista Capes PNPD, FESURV.
} 


\section{INTRODUÇÃO}

A cultura do girassolé uma boa alternativa para os agricultores no cultivo da segunda safra (safrinha), durante o período de entressafra da soja ou do milho, por exemplo. Essa cultura também apresenta umgrande potencial de crescimento no Brasil, principalmente considerando a crescente demanda por fontes energéticas. A importância da cultura é ressaltada visto que a agroenergia tem sido alvo de incentivo da política pública no país. Nesse cenário, o girassol, além de propiciar a obtenção de um óleo nobre, com alto valor nomercadoalimentício, também poderser usado com sucesso na obtenção de biodiesel (GAZZONI, 2005). No entanto, durante a safrinha, o girassol, assim como a maioria das culturas de segunda safra, geralmente sofre ataques severos de pragas, cujas populações aumentaram durante o período da safra. Assim, o girassol tem sido normalmente atacado por algumas pragas que migram da cultura anterior e infestam as plântulas ainda muito pequenase, portanto, sensíveis à injúria causada pelos insetos. Entre essas pragas, incluem-se a vaquinha Cerotoma arcuatus (Olivier) (Coleoptera: Chrysomelidae), as lagartas Anticarsia gemmatalis Hübner(Lepidoptera:Noctuidae)(MOsCARDI et al., 2005) e Spodoptera frugiperda (J.E. Smith) (Lepidoptera: Noctuidae) e a mosca-branca Bemisia tabaci (Gennadius) (Hemiptera: Aleyrodidae). Esta situação justifica a realização de pesquisas sobre métodos de controle dessas pragas, como por exemplo, o tratamento de sementes com inseticidas. Entretanto, além da eficiência do controle químico em tratamento de sementes, seu efeito sobre a fisiologia das sementes tem merecido constante atenção dos produtores epesquisadores, tendo em vista dificuldades encontradas para a obtenção de lotes de semente de boa qualidade.

Além de pesquisas dirigidas ao estudo das relações entre resultados de testes para a determinação da viabilidade (principalmente germinaçãoe tetrazólio), considerável volume de trabalho tem se concentrado em métodos para a avaliação do vigor, pois o potencial de armazenamento da semente, que é um dos componentes desua qualidade, édiretamenteafetado pelo vigor. Dessa forma, em várias pesquisas, as avaliações têm envolvido o uso de testes como o de envelhecimento acelerado (KULIK; YAKLICH, 1982; Marcos Filho et al., 1986). Todavia, ainda pouco se conhece sobre o efeito de inseticidas aplicados às sementes sobre a qualidade fisiológica, que podem determinar prejuízos à germinação e ao vigor das sementes. Estes efeitos podem depender do armazenamento de sementes após o tratamento com inseticidas, muitas vezes necessário até que haja comercialização e distribuição das mesmas. Este trabalho objetivou avaliar a eficiência do tratamento de sementes de girassol com inseticidas, visando o con- trole de $S$. frugiperda, A. gemmatalis, C. arcuatus e B. tabaci na fase inicial da cultura, em condições de casade-vegetação, e a influência destes produtos sobre a qualidade fisiológica das sementes após diferentes tempos de armazenamento.

\section{MATERIALEMÉTODOS}

Os experimentos foram conduzidos na Embrapa Arroz e Feijão, Santo Antônio de Goiás, GO, e no Laboratório deSementes doCentro FederaldeEducação Tecnológica (CEFET) de Rio Verde, GO. Os ensaios de eficiência foram conduzidos em casa-de-vegetação, em as parcelas experimentais infestadas artificialmente com as diferentes pragas estudadas ( $C$. arcuatus, A. gemmatalis, S. frugiperda e B. tabaci), constituídas por um vaso com seis plântulas de girassol BRS 122. Os ensaios foram conduzidos em delineamento experimental inteiramente casualizado, com dez tratamentos e dez repetições. Os tratamentos avaliados e as respectvas doses dos inseticidas, em $\mathrm{g}$ dei.a.edep.c. por $100 \mathrm{~kg}$ desementes, foram: tiodicarbe 600 gi.a. (Futur $300^{\circledR} 2 \mathrm{~L}$ ), tiodicarbe + imidacloprido $112,5+37,5$ g i.a. $\left(\right.$ Cropstar $\left.^{\circledR} 0,25 \mathrm{~L}\right)$, tiodicarbe + imidacloprido $157,5+52,5$ g i.a. (Cropstar ${ }^{\circledR} 0,35$ L), tiametoxam 210 gi.a. (Cruiser $350^{\circledR} 0,6 \mathrm{~L}$ ), tiametoxam 280 g i.a. (Cruiser $350^{\circledR} 0,8 \mathrm{~L}$ ), imidacloprido 245 g i.a. (Gaucho $350^{\circledR} 0,7 \mathrm{~L}$ ), fipronil 50 gi.a. (Standak ${ }^{\circledR} 0,2 \mathrm{~L}$ ), azadiractina $20 \mathrm{~g}$ i.a. $\left(\mathrm{NeemAzal}^{\circledR} 2 \mathrm{~L}\right.$ ), azadiractina 10 g i.a. (NeemAzal $\left.{ }^{\circledR} 1 \mathrm{~L}\right)$ e testemunha.

As lagartas e a moscas-brancas utilizadas nos experimentos foram provenientes de criação de laboratório e as vaquinhas foram provenientes de coleta realizada em campo. As sementes $(2 \mathrm{~kg})$ foram tratadas utilizando-se sacos plásticos para misturá-las com as doses testadas de cada produto. Osinseticidas tiodicarbe $600 \mathrm{~g}$ i.a. e azadiractina $10 \mathrm{e} 20 \mathrm{~g}$ i.a. foram aplicados diretamentenas sementes. Os demais eram primeiramente diluídos em $500 \mathrm{~mL}$ de água. Posteriormente, assementesforamagitadas por três minutos para garantir uma boa homogeneidade de sua cobertura. Após a emergência, as plantas foram infestadas com os insetos estudados quando apresentavam a primeira folha definitiva já desenvolvida. No ensaio com C. arcuatus foram utilizados dez adultos por repetição. Nos ensaios com lagartas de $S$. frugiperda foram utilizadas duas lagartas de $2^{\circ}$ ínstar por repetição, no primeiro ensaio, e duas lagartas de $3^{\circ}$ ou $4^{\circ}$ ínstar, no segundo ensaio. Oensaio com $A$. gemmatalis foi infestado com dez ovos próximos à eclosão das lagartas. Em todos os ensaios com lagartas e vaquinhas, foram utilizadas gaiolas de PVC (200 mm x 30 $\mathrm{cm}$ ) para confinar os insetos em cada unidade experimental. No ensaio com moscas-brancas, as plântulas foram infestadas colocando-se plantas previamente 
infestadas com a praga, ao redor do ensaio. Os parâmetros avaliados foram: número deinsetos vivos ou estande, de acordo com a praga estudada.

Nos ensaios realizados para analisar a qualidade fisiológica da semente, utilizou-se delineamento inteiramentecasualizado, em esquema fatorial $5 \times 10$ (cinco tempos de armazenamento e 10 inseticidas), com 4 repetições. Após o tratamento, as sementes foram armazenadas em sacos de papel Kraft, em condições normais de ambiente de laboratório. Antes do armazenamentoeum, dois, trêsequatromeses após, as sementes foram submetidas a testes de germinação, emergência e envelhecimento acelerado(vigor).

Oteste degerminaçãofoi conduzidocom 30 sementes por repetição, em rolos de papel-toalha tipo "Germitest", em germinador tipo "Mangesdorf", a $30^{\circ}$ C; a quantidade de água adicionada foi equivalente a 2,5 vezes o peso do substrato seco, visando umedecimento adequado e uniforme As avaliações foram efetuadas a partir do segundo dia após a semeadura, segundo os critérios estabelecidos nas Regras para Análise deSementes (BRASIL, 1992), computandose as porcentagens de plântulas normais, de germinação e o índice de velocidade de germinação (IVG).

Para o teste de emergência foram utilizadas bandejas com areia, umedecida com água destilada. Utilizou-se repetições de 30 sementes, semeadas em linhas distanciadas em $15 \mathrm{~cm}$, a uma profundidade de $3 \mathrm{~cm}$. Após a estabilização da emergência foi realizada a contagem das plântulas, a fim de se obter o IVE (Índice de Velocidade de Emergência) e a porcentagem de emergência.

Os resultados obtidos, quando necessário, foram transformados para que houvesse normalidade dos erros e homogeneidade das variâncias e, posteriormente submetidos à ANOVA. As médias, quando diferentes, foram comparadas pelo teste de Tukey, a $5 \%$ de probabilidade de erro. Para tempos de armazenamento das sementes foi realizada análise de regressão. A eficiência de controle foi calculada pela fórmula de Аввотт (1925).

\section{RESULTADOSEDISCUSSÃO}

Os resultados obtidos mostraram que $S$. frugiperda de $2^{\circ}$ ínstar é eficientemente controlada com o uso de tiodicarbe $600 \mathrm{~g}$ i.a. $/ 100 \mathrm{~kg}$ de sementes. Todos os demais produtos avaliados e respectivas doses foram ineficientes para o controle dessa praga. Entretanto, para o controle de $S$. frugiperda de $3^{\circ}$ e $4^{\circ}$ instar, a eficiência de tiodicarbe $600 \mathrm{~g}$ i.a. foi inferior a $40 \%$ (Tabela 1). Esses resultados mostram que essa praga é de difícil controle utilizando tratamento de sementes, principalmente quando a lagarta está em estágio avançado de desenvolvimento.

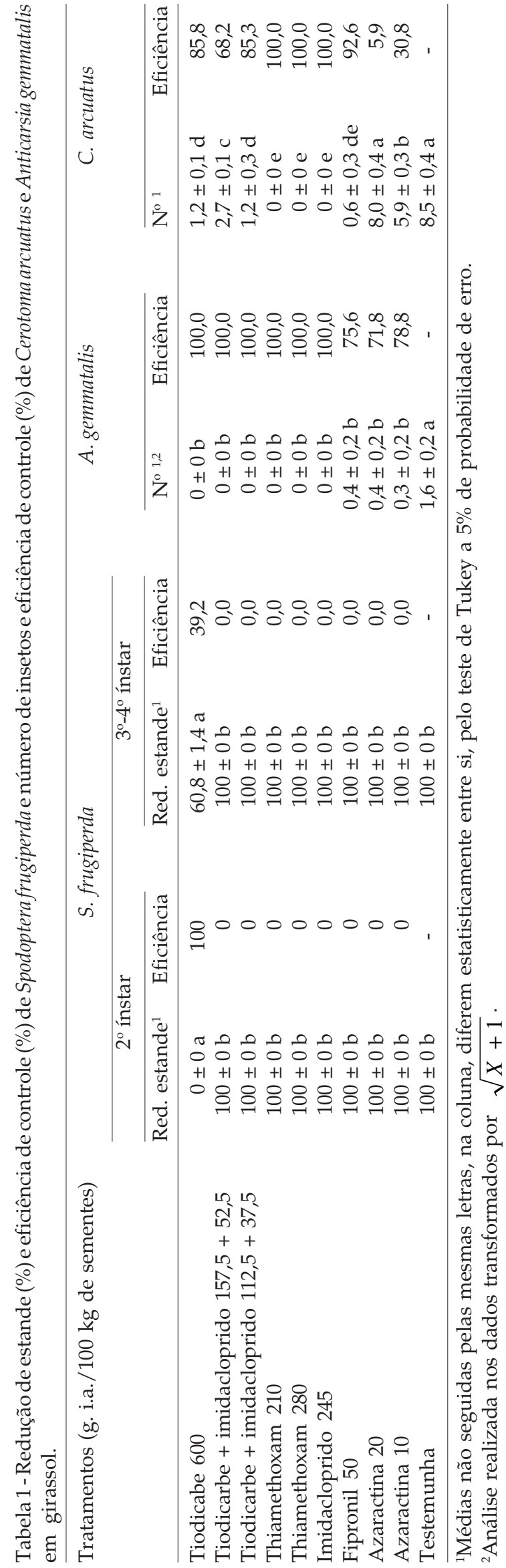


Tabela 2 - Número de ovos e ninfas de Bemisia tabaci biótipo B - soma das avaliações realizadas aos 7, 14, 21 e 28 dias após a germinação, realizadas em $4 \mathrm{~cm}^{2}$ e eficiência de controle (Abbott) (\%).

\begin{tabular}{|c|c|c|c|c|}
\hline \multirow[t]{2}{*}{ Tratamentos(g i.a./100 kg de sementes) } & \multicolumn{2}{|c|}{ Ovos } & \multicolumn{2}{|c|}{ Ninfas } \\
\hline & № de ovos ${ }^{1,2}$ & Abbott (\%) & № de ninfas ${ }^{1,2}$ & Abbott (\%) \\
\hline Tiodicabe 600 & $65,22 \pm 16,36^{\mathrm{ns}}$ & 0,00 & $20,33 \pm 3,44^{\mathrm{ns}}$ & 12,14 \\
\hline Tiodicarbe+imidacloprido $157,5+52,5$ & $61,00 \pm 9,23$ & 0,00 & $21,00 \pm 3,30$ & 9,24 \\
\hline Tiodicarbe+imidacloprido $112,5+37,5$ & $55,00 \pm 9,79$ & 0,00 & $25,38 \pm 3,85$ & 0,00 \\
\hline Thiamethoxam 210 & $38,57 \pm 7,79$ & 15,73 & $29,70 \pm 4,96$ & 0,00 \\
\hline Thiamethoxam 280 & $46,56 \pm 6,94$ & 0,00 & $29,10 \pm 4,02$ & 0,00 \\
\hline Imidacloprido 245 & $34,10 \pm 6,79$ & 25,50 & $14,56 \pm 2,89$ & 37,80 \\
\hline Fipronil 50 & $53,13 \pm 19,16$ & 0,00 & $23,33 \pm 8,11$ & 0,00 \\
\hline Azaractina 20 & $41,60 \pm 6,64$ & 9,11 & $17,10 \pm 2,58$ & 26,10 \\
\hline Azaractina 10 & $46,89 \pm 9,83$ & 0,00 & $28,50 \pm 6,48$ & 0,00 \\
\hline Testemunha & $45,77 \pm 8,33$ & - & $23,14 \pm 5,25$ & - \\
\hline
\end{tabular}

${ }^{1}$ ns: diferenças não significativas.

${ }^{2}$ Análise realizada nos dados transformados por $\sqrt{X+1}$.

Lagartas de S. frugiperda são facilmente encontradas atacando plantas recém germinadas de girassol principalmente em plantio direto ou o cultivo mínimo, sistemas de plantio normalmente adotados na região Centro-Oeste. Nesse cenário, S. frugiperda tem se beneficiado, pois tem a capacidade de se reproduzir e completar o desenvolvimento nas plantas de milho ou milheto e atacar plantas recém-emergidas da safrinha de girassol cultivado após a colheita dessas culturas, causando redução de estande. Nesse contexto, na cultura do girassol, a proteção do estande é de extrema importância, visto que a população de plantas de girassol utilizada por hectare é pequena

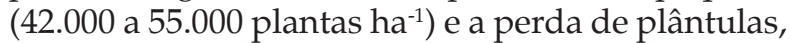
devido ao ataque de pragas, causa prejuízos econômicos significativos.

Uma das técnicas que tem sido utilizada para minimizar os danos causados por insetos é a utilização de inseticidas junto à dessecação, antes do plantio. Geralmente, os agricultores utilizam inseticidas de menor custo nessa pulverização, como os do grupo dos piretroides, os quais, normalmente, não são seletivos aos inimigos naturais e prejudicam o controle biológico natural, e podem causar problemas adversos como a resistência de pragas a inseticidas, surtos de pragas secundárias e a rápida ressurgência de pragas (BuENO et al., 2010; CARMO et al.,2010). Contudo, o tratamento de sementes utiliza baixa dose por hectare e é seletivo ecologicamente à maioria dos inimigos naturais e insetos benéficos (SANTOS et al., 2006). Sendo assim, mesmo que a eficiência do tiodicarbe na dose de $600 \mathrm{~g}$ i.a. $/ 100 \mathrm{~kg}$ sementes não tenha atingido $80 \%$ de controle das lagartas de $S$. frugiperda de $3^{\circ} \mathrm{e} 4^{\circ}$ instar, a utilização dessa técnica de controle pode ser, ainda, uma boa alternativa no controle do ataque inicial da praga, principalmente se associada a outras táticas de manejo, como um pequeno intervalo de tempo (pousio), entre o plantio da primeira e da segunda safra. Esse período de pousio entre o cultivo da safra e safrinha, deixa a praga sem alimento fazendo com que à mesma migre para outras áreas ou morra pela ausência de alimentação. Esse efeito aliado ao controle químico realizado pelo tratamento de sementes reduzirá o ataque inicial da mesma ao cultivo subseqüente (PEDIGO, 2002). Resultados semelhantes aos obtidos nesta pesquisa com o uso de tiodicarbe foram relatados por OliveIRA et al. (2008) para a cultura do milho, no controle de Dalbulus maidis, em que os autores verificaram a eficiência de $100 \%$ para o tratamento de sementes com esse inseticida. Tiodicarbe também foi um dos melhores tratamentos nos resultados obtidos por CAMILLO et al. (2005) para controle de $S$. frugiperda na cultura do milho através do tratamento de sementes.

A lagarta-da-soja A. gemmatalis, que eventualmente ataca a cultura do girassol (MOSCARDI $e t$ al., 2005), principalmente quando as mariposas se dispersam das plantas da soja para a cultura do girassol safrinha, após a colheita da soja, poderá ser controlada de maneira eficiente quando a lagarta estiver ainda no primeiro ínstar utilizando-se a maioria dos tratamentos testados neste experimento. Apenas o fipronil e a azadiractina apresentaram eficiência menor que $80 \%$ de controle para $A$. gemmatalis (Tabela 1), o que demonstra a viabilidade do uso do tratamento de sementes para manejar os ataques iniciais dessa lagarta. 


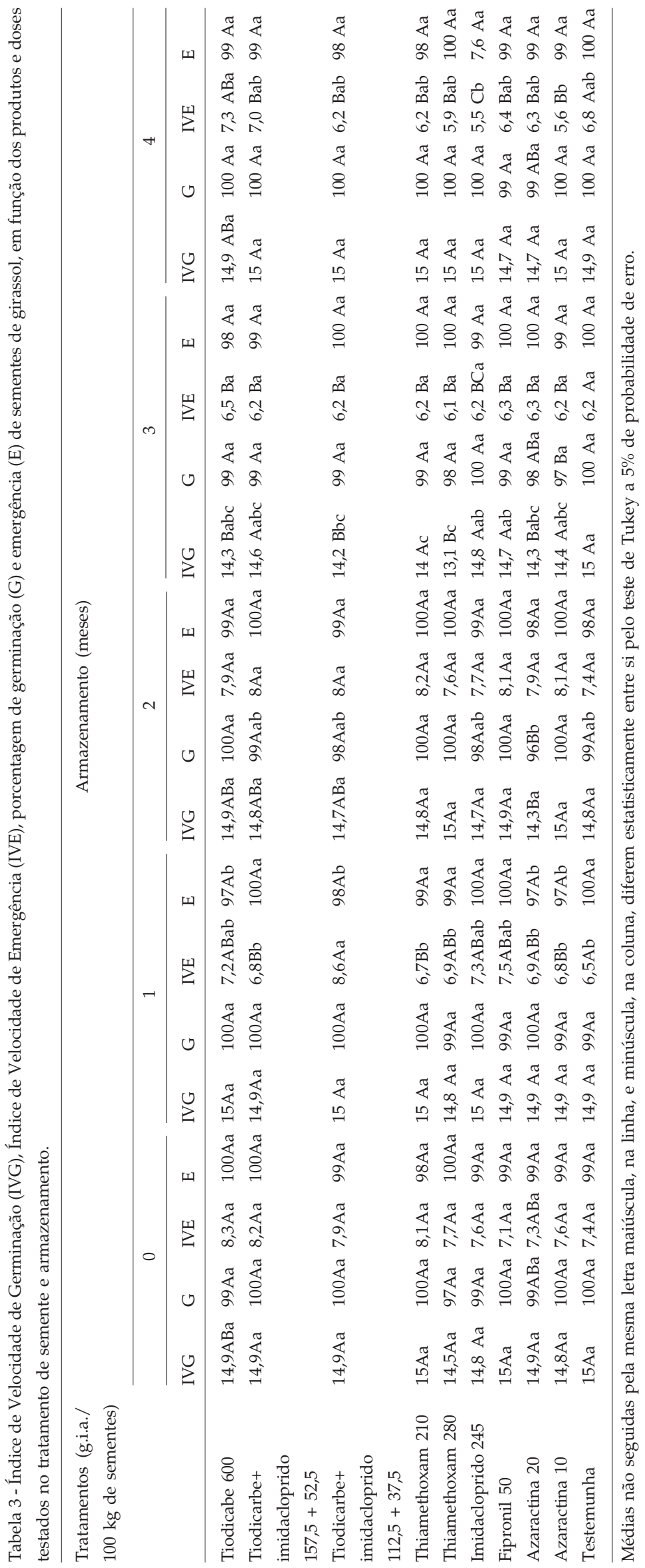


Todicarbe $600 \mathrm{~g}$ ia.

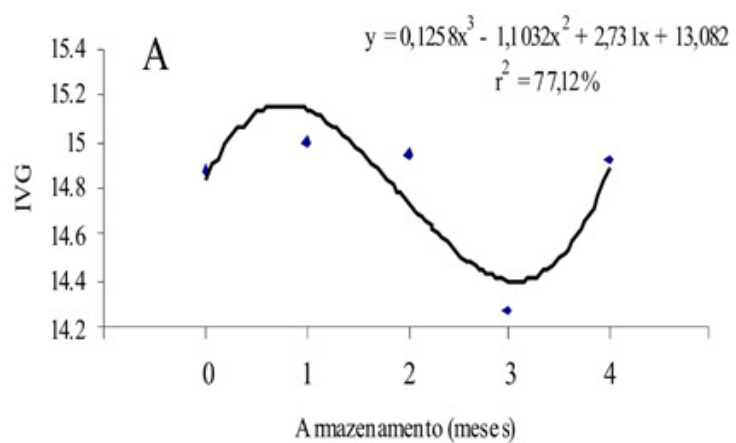

Thimethoxam $210 \mathrm{~g}$ ia.
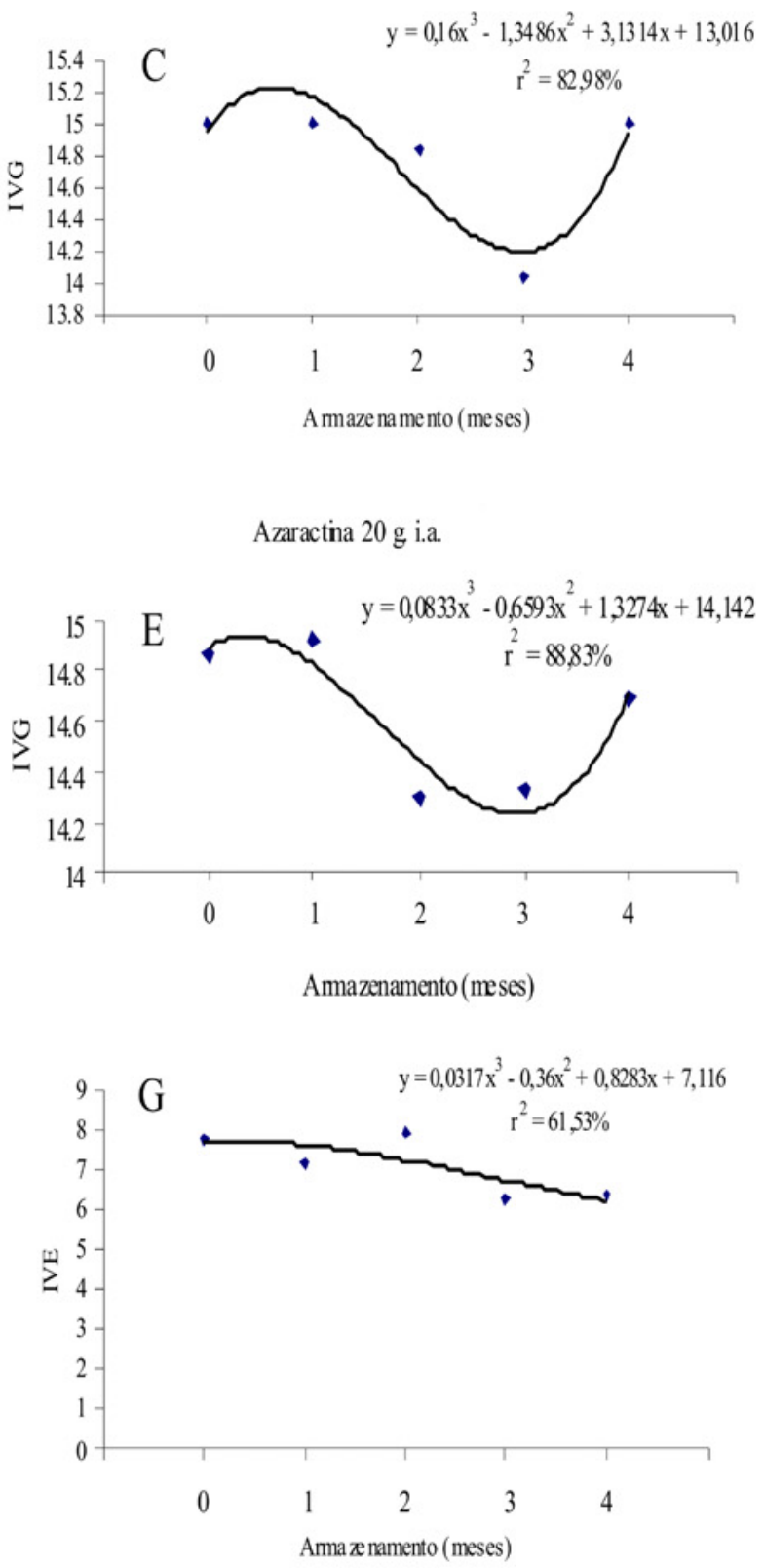

Todicarbe + midaclopido $112,5+37,5 \mathrm{~g}$. ia.

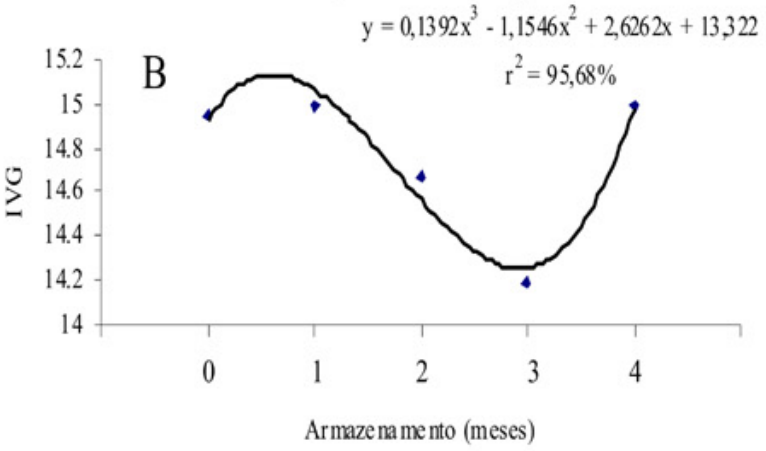

Thiamethoxam $245 \mathrm{~g}$. ia.
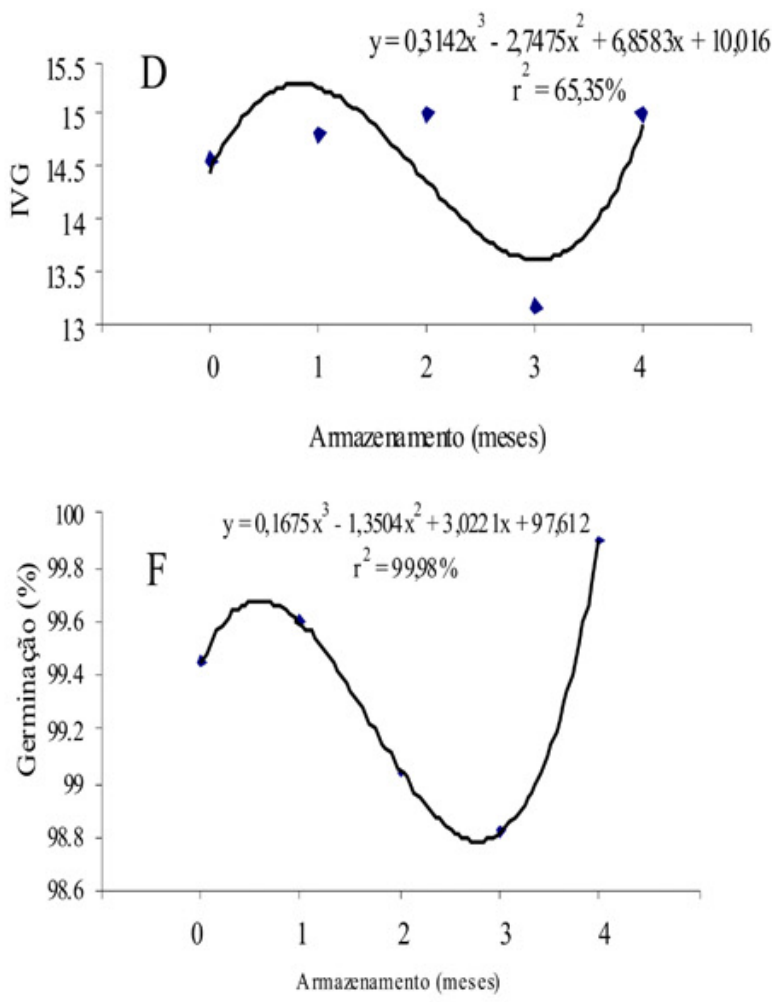

Fig. 1 - Análise de regressão realizada no desdobramento dos diferentes inseticidas para o Índice de Velocidade de Germinação (IVG) (A, B, C, D e E), germinação (F) e Velocidade de Emergência (IVE) (G). 
Os tratamentos de tiodicarbe $600 \mathrm{~g}$ i.a., tiodicarbe + imidacloprido 157,5 + 52,5 g i.a., tiametoxam 210 e $280 \mathrm{~g}$ i.a., imidacloprido $245 \mathrm{~g}$ i.a. e fipronil $50 \mathrm{~g}$ i.a./ $100 \mathrm{~kg}$ de sementes apresentaram acima de $80 \%$ de controle deadultos da vaquinha C.arcuatus (Tabela 1 ), cuja ocorrência tem sido citada no início do desenvolvimento das plantas de girassol, causando um desfolhamento expressivo (MOsCARDI et al. 2005). No entanto, para a mosca-branca, nenhum dos tratamentos estudados mostrou-se eficiente para ser utilizado no seu manejo (Tabela 2). A baixa eficiência no controle da mosca-branca pode estar relacionada com problemas de resistência a alguns ingredientes ativos, principalmente do grupo dos neonicotinoides, devido ao seu uso abusivo na agricultura, para o controle desse inseto, por vários anos consecutivos, o que evidencia que novas pesquisas precisam ainda ser conduzidas para avaliar a evolução da resistência da mosca-branca ao controle químico utilizado. Por outro lado, a baixa eficiência no controle da moscabranca de outros produtos que não sejam sistêmicos como o fipronil, por exemplo, podeestar associado ao fato da baixa movimentação do ingrediente ativo na planta impossibilitando a contaminação do inseto com o produto.

Em relação aos testes de qualidade fisiológica das sementes, apenas as sementes armazenadas por dois e três meses apresentaram diferenças no Índice de VelocidadedeGerminação(IVG) ena porcentagem de germinação (Tabela 3). Aos dois meses de armazenamento, sementes tratadas coma azadiractina (20 gi.a./100 kgdesementes) apresentaram menor IVG e porcentagem de germinação, em relação aos demais produtos e doses testados, sendo que as sementes tratadas com tiodicarbe + imidacloprido $(157,5+52,5 \mathrm{~g}$ i.a. $/ 100 \mathrm{~kg}$ desementes), imidacloprido (245 gi.a./100 $\mathrm{kg}$ de sementes) e azadiractina (20 g i.a. $/ 100 \mathrm{~kg}$ de sementes) apresentaram as menores taxas degerminação causadas pela ação dos inseticidas. Aos três meses de armazenamento, as sementes tratadas com azadiractina (20 g i.a./100 kg de sementes) também apresentaram menor IVG. Os produtos tiodicarbe + imidacloprido (112,5 + 37,5 g i.a./100 kg de sementes) e azadiractina ( $10 \mathrm{~g}$ i.a. $/ 100 \mathrm{~kg}$ de sementes) foram os queapresentaram porcentagem degerminaçãoinferior. Sementes tratadas com tiametoxam (280 g i.a. / 100 $\mathrm{kg}$ de sementes) apresentaram o pior IVG, aos três meses de armazenamento, seguidas por sementes tratadas com tiodicarbe (600 g i.a./100 kg de sementes), tiodicarbe + imidacloprido $(112,5+37,5$ g i.a. $/ 100 \mathrm{~kg}$ de sementes), azadiractina (10 e $20 \mathrm{~g}$ i.a. $/ 100 \mathrm{~kg}$ de sementes)etiametoxam(210gi.a./100 kg desementes).

Analisando-se o IVG para os tratamentos com inseticidas tiodicabe $600 \mathrm{~g}$ i.a. $/ 100 \mathrm{~kg}$ de sementes; tiodicarbe+imidacloprido $112,5+37,5$; thiamethoxam 210; thiamethoxam 280; azaractina 20 gi.a. $/ 100 \mathrm{~kg}$ de sementes, verificou-se um decréscimo nele entre dois equatro meses de armazenamento, sendo o pior índice de velocidade de germinação verificado no tempo de quatro meses. (Figs. 1A a 1E). Na porcentagem de germinação foi verificado o mesmo efeito que o IVG aos dois e quatro meses de armazenamento. As sementes armazenadas por cinco meses apresentaram porcentagem degerminação superior às demais (Fig. 1F).

Para oIVEe a porcentagem deemergência, apenas as sementes armazenadas por um, três e quatro meses apresentaram diferenças (Tabela3). No primeiro mês, apenas o produto tiodicarbe + imidacloprido $(112,5+$ $37,5 \mathrm{~g}$ i.a. $/ 100 \mathrm{~kg}$ de sementes) mostrou-se superior para o IVE. Aos quatro meses de armazenamento, tiodicarbe (600 gi.a. $/ 100 \mathrm{~kg}$ de sementes), tiodicarbe + imidacloprido $(157,5+52,5$ g i.a. $/ 100 \mathrm{~kg}$ de sementes) ea testemunha também foram os tratamentos que apresentaram os maiores IVEs. Sementes armazenadas por um mêse tratadas com os produtos (tiodicarbe (600 g i.a./100 kg de sementes), azadiractina (10 g i.a. $/ 100 \mathrm{~kg}$ de sementes), azadiractina (20 g i.a. $/ 100$ $\mathrm{kg}$ de sementes) e tiodicarbe + imidacloprido (112,5+ 37,5 g i.a. $/ 100 \mathrm{~kg}$ de sementes), apresentaram menor porcentagem deemergência. Todos os produtos testados exerceram influência negativa sobre o índice de velocidade de emergência, em algum tempo de armazenamento, exceto na testemunha, antes do armazenamento e, também, nas armazenadas por dois meses. Para o índice de velocidade de emergência, houve pouca variação no índice, com uma pequena tendência de queda ao longo do armazenamento (Fig. 1G). É importante ressaltar que, apesar da diferença estatística entre os tempos de armazenamento, em todos estes foi verificada uma elevada porcentagem de germinação (de 98,8 a 99,9\%), podendo-se concluir que durante os períodos de armazenamento avaliados não houve prejuízos para a qualidade fisiológica da semente.

Para tratamento de sementes de milho com fungicidas, resultados semelhantes aos desta pesquisa foram relatados por Luz; Pereira (1998), quando os autores observaram um aumento de germinação e rendimento da cultura do milho, devido aos tratamentos utilizados. Silva et al. (1996) estudaram o efeito dos inseticidas clorpirifós, carbossulfam e tiodicarbe, aplicados nas sementes de milho, e concluíram que o armazenamento das sementes tratadas reduziu a germinação e o vigor.

\section{CONCLUSÕES}

Conclui-se que a lagarta de S. frugiperda pode ser controlada com o uso de tiodicarbe $600 \mathrm{~g}$ i.a./ $100 \mathrm{~kg}$ de sementes quando se encontram-se no $2^{\circ}$ ínstar, 
sendo que para lagartas de $3^{\circ}$ e $3^{\circ}-4^{\circ}$ ínstar dessa praga não foi verificado controle com os tratamentos testados. Os melhores tratamentos no controle de $A$. gemmatalis e de C. arcuatus foram tiodicarbe $600 \mathrm{~g}$ i.a., tiodicarbe + imidacloprido $112,5+37,5$ gi.a., tiodicarbe + imidacloprido 157,5 + 52,5 g i.a., tiametoxam $210 \mathrm{~g}$ i.a., tiametoxam 280 g i.a., e imidacloprido 245 g i.a., além de fipronil $50 \mathrm{~g}$ i.a./100 kg de sementes apenas para C. arcuatus. No controle de B. tabaci nenhum dos tratamentos testado foi eficiente. Durante os períodos dearmazenamento avaliados (até quatro meses após o tratamento) os inseticidas avaliados não prejudicaram a qualidade fisiológica da semente (germinação e a emergência das sementes).

\section{AGRADECIMENTOS}

Aos pesquisadores Ivan Carlos Corso e César de Castro (Embrapa Soja, Londrina, PR) pelo auxílio na elaboração do manuscrito e ao professor José Waldemar da Silva (CEFET, Rio Verde, GO) pelo auxílio na análise estatística. À Embrapa Arroz e Feijão pelo apoio na realização do trabalho. AoComitê de Publicações da Embrapa Soja pela revisão e aprovação do artigo, sob o número 07/2008.

\section{REFERÊNCIAS}

ABBOTT, W.S. A method of computing the effectiveness of an insecticide. Journal of Economic Entomology, v. 18, p. 265-267, 1925.

BRASIL. Ministério da Agricultura e Reforma Agrária. Regras para análise de sementes. Brasília, 1992.

BUENO, A.F.; CORRÊA-FERREIRA, B.S.; BUENO, R.C.O. Controle de pragas apenas com o MIP. A Granja, p. 76 - 78, jan/2010.

CAMILLO, M.F; DI OLIVEIRA, J.R.G.; BUENO, A.F.; BUENO, R.C.O.F. Tratamento de sementes na cultura do milho para o controle de Spodoptera frugiperda. Ecossistema, v.30, n.1/2, p.59-63, 2005.

CARMO, E.L.; BUENO, A.F.; BUENO, R.C.OF. Pesticide selectivity for the insect egg parasitoid Telenomus remus. BioControl (Dordrecht), 21 fev., 2010.

GAZZONI, D.L. Óleo de girassol como matéria-prima para biocombustíveis. In: LEITE, R.M.V.B.C.;
BRIGHENTI, A.M.; CASTRO, C. (Ed.). Girassol no Brasil. Londrina: Embrapa Soja, 2005. p.145-162.

KULIK, M.M.; YAKLICH, R.W. Evaluation of vigor tests in soybean seeds: relationship of accelerated aging, cold, sand bench and speed of germination tests to field performance. Crop Science, v.22, n.4, p.766-770, 1982.

LUZ, W.C.; PEREIRA, L.R. Tratamento de sementes com fungicidas relacionados com o controle de patógenos e rendimento de milho. Ciência Rural, v.28, n.4, p.537-541, 1998.

MARCOS FILHO, J.; CÍCERO, S.M.; SILVA, V.R. Qualidade fisiológica e comportamento de sementes de soja no armazenamento e no campo. Anais da Escola Superior de Agricultura "Luiz de Queiroz", v.43, p.389$443,1986$.

MARCOS FILHO, J.; CÍCERO, S.M.; SILVA, V.R. Avaliação da qualidade das sementes. Piracicaba: FEALQ, 1987. 230p.

MOSCARDI, F.; SOSA-GOMEZ, D.R.; CORSO, I.C. Invertebrados associados ao girassol e seu manejo. In: LEITE, R.M.V.B.C.; BRIGHENTI, A.M.; CASTRO, C. (Ed.). Girassol no Brasil. Londrina: Embrapa Soja, Londrina. 2005. p.470-500.

OLIVEIRA, C.M.; OLIVEIRA, E.; CANUTO, M.; CRUZ, I. Eficiência de inseticidas em tratamento de sementes de milho no controle da cigarrinha Dalbulus maidis (Hemiptera: Cicadellidae) em viveiro telado. Ciência Rural, v.38, n.1, p.231-235, 2008.

PEDIGO, L.P. Entomology and pest management. New Jersey: Prentice Hall, 2002. 742p.

SANTOS, A.C.; BUENO, A.F.; BUENO, R.C.O.F. Seletividade de defensivos agrícolas aos inimigos naturais. In: PINTO, A.S.; NAVA, D.E.; ROSSI, M.M.; MALERBO-SOUZA, D.T. (Ed.). Controle biológico de pragas na prática. Piracicaba, 2006. p.221-227.

SILVA, F.M.A.; MELO, P.C.; CARVALHO, R.L. Efeito de inseticidas na germinação e vigor de sementes de milho (Zea mays L.) em duas épocas de armazenamento. In: CONGRESSO NACIONAL DE MILHO E SORGO, 21., 1996, Londrina. Resumos. Londrina: IAPAR, 1996. p.276.

Recebido em 15/10/08

Aceito em 17/3/10 